\title{
Dynamic and reactive optimization of physical and financial flows in the supply chain
}

\author{
Amira Brahmi ${ }^{a *}$, Atidel B. Hadj-Alouane ${ }^{a}$ and Sami Sboui ${ }^{b}$
}

${ }^{a} U R$ OASIS, Ecole nationale d'ingénieurs de Tunis, Université de Tunis El Manar, 1002 Tunis, Tunisia ${ }^{b} J A S S P$ SAS, 1 rue Albert Einstein 77420 Champs sur Marne, France

\begin{tabular}{l}
\hline C H R O N I C L E \\
\hline Article history: 132019 \\
Received May 13 \\
Received in Revised Format \\
June 42019 \\
Accepted June 102019 \\
Available online \\
June 112019 \\
\hline Keywords: \\
Mixed-integer programming \\
Payment term \\
Trade credit \\
Logistics \\
Quantity flexible contract \\
Factoring
\end{tabular}
A B S T R A C T

\begin{abstract}
This article presents a new approach to address the problem of joint planning of physical and financial flows. The main contribution of this work is that it integrates supply chain contracts and also focuses on supply chain tactical planning in an uncertain and disrupted environment, taking into account budgetary and contractual constraints. In order to minimize the effect of disturbances due to existing uncertainties, a planning model is developed and implemented on a rolling horizon basis. The goal is to seek the best compromise between the available decisionmaking levers linked with physical and financial flows by adopting a dynamic process that allows for data update at each planning stage. The results of the implemented approach are analysed to highlight the benefits incurred by the inter-firm collaboration in terms of operational performance and working capital (WC) of the supply chain. Our approach represents a basis for negotiation with the suppliers in order to yield a possibly shared profit.
\end{abstract}

\section{Introduction}

The evolution of the economic context, the difficulties of access to credit and the multiplication of operational and financial risks are becoming major concerns for most organisations. Particularly, during the recent economic downturn, firms are suffering from the lack of credit and the increasing cost of borrowing. Hence, one of the most important tasks for today's managers is that internal sources of cash as the availability of credit is limited. Many small and medium size companies may not have the working capital reserves needed to finance their operations (Protopappa-Sieke \& Seifert, 2017) and find themselves at an increasingly high risk of going out of business. Companies have become aware that it is of a great importance to extract liquidity through an efficient management of working capital requirement (Comelli et al., 2008; Mian \& Smith, 1992; Yi \& Reklaitis, 2004).

In spite of its importance for business solvency, working capital management has been neglected by the literature on supply chain management. As stated by Bal et al. (2018), "Often the logistics manager allocates much effort and costs to shorten lead times by hours, just to learn that large customers force the sales manager to accept credit extensions in the range of months". For example, understanding the impact

* Corresponding author



2020 Growing Science Ltd.

doi: $10.5267 /$ j.ijiec.2019.6.003 
of upstream and downstream payment delays within the supply chain can result in a better visibility of both cash and product flows and thus can enhance working capital utilization and reduce working capital requirements (Protopappa-Sieke \& Seifert, 2017; Dada \& Hu, 2008).

There is a plethora of literature on supply chain management. However, the aspects related to financial flows are often overlooked (Guillen et al., 2006; Lainez et al., 2009; Longinidis and Georgiadis, 2011; Longinidis \& Georgiadis, 2013). The existing literature has focused on the optimization of physical flows through the supply chain, by considering logistical costs such as production, storage, transportation, shortage, etc. More recently, the literature on supply chain management has reflected a growing awareness of the intertwinement of financial and operational decisions, and the influence of the financing structure on the revenues of actors in the supply chain, as well as their overall performance (Chen \& Hu, 2011). Indeed, variations between incoming and outgoing cash flows of a company are generated by the physical flows: cash outflows correspond to cash outlay related to supplier orders, while cash inflows correspond directly to cash recovery related to customer deliveries. This observation shows the importance of taking into account the financial consequences involved by the operation decisions. It is therefore necessary to coordinate operational and financial decisions.

Financial flows are often treated in a disconnected way from the physical flows. Companies consider the decisions from the operations management's point of view, such as inventory, capacity requirements, ordering, pricing, etc., and consider treasury as an infinite source. The execution of such decisions influences the financial performance in terms of gross profit, working capital requirement and return on investment. Indeed, the availability of cash governs the production decisions made by firms. A production plan may lead to infeasible execution if it violates the minimum cash flow imposed by the firm and causes a temporary lack of liquidity (Puigjaner \& Guillèn, 2008). Consequently, the coupling of finance and physical flows enables firms to avoid insolvency risk within the supply chain, and hence reduces the financing costs. Moreover, financial supply chain management and working capital management are increasingly recognized as important avenues to increase profitability and reduce supply chain costs (Protopappa-Sieke \& Seifert, 2010; Deloof, 2003; Zeballos et al., 2013).

Moreover, the joint management of physical and financial planning may not be enough to meet the supply chain financing need. In the absence of collaboration, the overall cost of financing the supply chain is unnecessarily high (Grossman \& Hart, 1986). The physical and financial flows are more profitable for companies when they are highly integrated within a collaboration context throughout the supply chain (Pfohl and Gomm, 2009). Thus, customer-supplier collaboration ultimately leads to an improvement in the company's financial performance (Meltzer, 1960; Cao \& Zhang, 2010).

Our work is concerned with the interface of supply chain and financial management. We develop a model that considers the supply chain planning problem taking into account budget constraints, relations between firms, and demand uncertainties. We propose a model for planning physical flows by integrating financial flows. We focus on working capital and liquidity optimization. To cope with the uncertainty of demand, the model is based on a dynamic process with a rolling horizon, which takes into account the potential for reactivity of the company and its suppliers in the form of anticipation times. The objective of the model is to maximize the change in the global net working capital.

The rest of the paper is organized as follows. Section 2 presents the literature review relevant to our research. Model assumptions and study context are described in Section 3. A mathematical model is proposed in Section 4. Experiments and results are presented in Section 5. We finally report the conclusions of this work.

\section{Literature review}

A key target for the intertwinement of physical and financial decisions is to ensure solvency and react efficiently against uncertainties. Moreover, the non-consideration of a decision outcome on both physical and financial flows can lead to a biased result. For example, companies may request to increase their suppliers' reactivity to compensate for an excessive decrease in inventories caused by a suboptimal working capital management. However, improving the procurement lead time might lead to 
counterproductive outcomes. The supplier may require a higher price for that added flexibility. This is particularly critical when purchasing costs constitute a significant portion of the production costs.

In an attempt to cope with these problems, we propose to consider the coordination with suppliers through contractual mechanisms. The flexibility in arrangements can be a potential solution to find a good tradeoff between the financial and the operational performance. In the following, we will explore supply chain models with financial considerations and the integration of supply chain contracting.

\subsection{Supply chain modelling with financial considerations}

Given the complexity of integrating operational and financial decisions, little research has been conducted in this area.

Romero et al. (2003) and Badell et al. (2004) were among the first authors who integrated financial aspects into supply chain management. Their work demonstrated the importance of assessing the level of liquidity of entities during the planning and scheduling process. Romero et al. (2003) developed a deterministic multi-period mathematical model that combines scheduling and planning decisions with cash flow and budget management. Badell et al. (2004) added the management of payments and investments. The objective function of the proposed model was to maximize the net value of revenues gained throughout cash transactions over the planning horizon. Moreover, the model considered the satisfaction of customer's due dates and prompt payment discounts. Thus, financial decisions such as the best scheduling of payments, investments and sales of marketable securities were included.

Guillén et al. (2006) proposed a mixed integer linear program (MILP) model for a multi-product, multiechelon chemical supply chain, which integrates a scheduling/planning model with a cash flow optimization model. The novelty of their approach lies in the integration of the financial aspects, and the use of a financial performance indicator as the objective function. Indeed, the objective function consists in maximizing the change in equity of the firm. The choice of this objective aims to increase the shareholder value of the company.

Puigjaner and Guillén- Gosálbez (2008) integrated a simulation model with an optimization algorithm. The authors developed an agent-based application to capture all the processes in a chemical chain. Thus, the model included environmental and financial aspects. A financial model was constructed to incorporate the financial aspects, and it was connected to the multi-agent system through payments of raw material, production and transportation services, and the sale of products. The mathematical formulation used in the financial model was taken from the work of Guillén et al. (2006). The complexity of such a problem induced the use of a multi-objective genetic algorithm.

Lainez et al. (2007) formulated a deterministic mixed integer linear programming model to design a chemical supply chain that takes into account process operations and budgetary constraints. The authors aimed at maximizing the corporate value by applying the discounted cash flow method. Puigjaner and Lainez (2008) extended this model to consider demand uncertainties, prices and interest rates. The authors used stochastic programming combined with control theory to model the problem.

Unlike previous works, the models presented by Longinidis and Georgiadis (2011), Longinidis and Georgiadis (2013) and Steinrücke and Albrecht (2016) do not consider payment scheduling to optimize the cash flow. Indeed, the authors focused on optimizing the financial statement of the supply chain. Longinidis and Georgiadis (2011) proposed a supply chain network design model that incorporates financial statement analysis modeling through financial ratios. The model considered uncertainty in products demands through a scenario analysis. The objective was to maximize the shareholder value of the company taking into account operations and financial constraints. Longinidis and Georgiadis (2013) extended this model to an uncertain economic context by introducing the probability of credit default. The proposed model is a mixed nonlinear program integrating Altman's z-score and added economic value. The main novelty of this approach is that the weighted average cost of capital of the company is optimized and not considered as an estimated exogenous variable. Steinrücke and Albrecht's (2016) model aimed to determine annual payouts to an investor while integrating supply chain planning and 
financial planning. Logistics planning included site liquidation and opening, capacity adjustments, sales markets, supplier selection and supply chain operations. The model is based on the flow-to-equity discounted cash flow method. The objective is to maximize the present value of the equity while determining the annual cash outflows to the institutional investor during his commitment. Solvency constraints are integrated through financial balancing between all cash inflows and outflows related to dividend payouts to the investor.

Sharma et al. (2011) considered a mixed-integer linear program integrating logistics and financial supply chain planning. The authors aimed at maximizing the shareholder value of the company. Constraints on financial ratios are used to limit the solution space of the model.

Longinidis et al. (2015) introduced operational hedging strategies for firms that face both exchange rate and demand uncertainties. The operational hedging are used to mitigate exchange rate fluctuations. The authors developed a mixed integer stochastic program for optimal supply chain network design and operation. They proposed compensation techniques for the rationalization of inflows and outflows of currencies when the net position of foreign currency flows is exposed to risk. Compensation actions are triggered through closing facilities, terminating purchasing contracts with suppliers, and leaving a fraction of demand unfulfilled. The model does not satisfy all demands to avoid entries in undervalued currency and aimed at minimizing operational and currency risk exposure costs.

These previous research works demonstrated the importance of optimizing the financial chain during the planning and scheduling process. However, existing studies do not take into account the effect of flexibility in lead times on financial performances. As a company manages to shorten its operating cycle time, the reduced time lag between disbursement and receipts of money decreases the financing needs. We will focus on the effect of reducing lead times on releasing the locked up capital in the operating cycle.

\subsection{Supply chain contracting}

The literature on logistics suggests that the use of suitable coordination mechanisms helps to improve the overall performance of the supply chain.

The main mechanism of coordination analysed in the literature is the contracts between suppliers and buyers. Collaboration is implemented through contractual agreements, focusing on delivery times, quantity, payment policy and prices (Hofmann, 2005).

One of the main objectives of our work is to illustrate the impact of the decisions taken during these contractual commitments on the physical and financial flows. We will limit our study to two types of contracts: Quantity Flexibility Contracts (QF) and trade credits.

\subsubsection{Quantity Flexibility (QF) Contracts}

Supply contracts can provide flexibility in terms of quantity, price or lead-time between the supplier and the buyer. The contracts that incorporate a flexibility mechanism help to reduce the inadequacy between supply and demand, thus increasing the supply chain performance. One of the most popular flexibility contracts is quantity flexibility, in which the order can be adjusted following a better knowledge of the final demand (Shen et al., 2018). We will restrict ourselves to the so-called rolling horizon flexibility (RHF) contracts, which is the most relevant for our study and widely used in practice. There are many literature reviews on this field, including the one presented by Tsay and Lovejoy (1999). By this quantity flexibility arrangement, the buyer commits to the quantities to be ordered for each period of the planning horizon based on forecasts. Generally, the supplier allows limited flexibility to the buyer to adjust the current order and future commitments by a rolling horizon procedure allowing a periodic update of the data (Bassok \& Anupindi, 2008). The objective of these contracts is to limit the variability in orders intake despite the high uncertainty on future demand. Tsay and Lovejoy (1999) presented a quantity flexibility contracts in a two-echelon supply chain with periodic update of demand forecast information using a rolling horizon planning. The authors analysed the impact of these contracts 
on supply chain flexibility, inventory levels and the bullwhip effect. They demonstrated the potential gains from using flexible orders on each member of the supply chain. Sethi et al. (2004) used the same idea for a multi-period case. They derived the optimal initial order and the revised optimal quantities based on the updates of demand forecasts. Walsh et al. (2008) examined the effect of sharing information about future uncertain demand between the original manufacturer and a subcontractor on the operational performance under a rolling horizon flexibility (RHF) contracts. They presented two types of contracts: the first with constant flexibility limits and the second with decreasing flexibility limits. Bassok and Anupindi (2008) provided a thorough analysis of rolling horizon flexibility contracts between customer and supplier. They measured the effect of flexibility on customer satisfaction. Lian and Deshmukh (2009) focused on supply contracts under which a buyer receives discounts for committing to purchase in advance in the context of quantity flexibility contracts. They developed a finite-horizon dynamic programming model to determine the optimal replenishment strategy and order quantities that minimize the total cost of the buyer at each period of the rolling horizon. Kim et al. (2014) proposed a linear model to analyse the buyer's decision in the context of a rolling horizon flexibility contract. Gallassso et al. (2009) studied contracts with flexibility on quantities to supply. The originality of their approach lies in the definition of a specific firm horizon for each decision. They measured the impact of these parameters on the reactivity of the supply chain through a simulation approach.

\subsubsection{Trade credit policies}

The last financial crisis period and the decrease in liquidity in the market caused a considerable reduction in the granting of loans. Klapper et al. (2011) showed that companies with a cash surplus can thus replace traditional financing with trade credits (credit between firms). Trade credit is often used when it becomes difficult to obtain credit from financial institutions.

Inter-firm finance ranks among the most important sources of financing for small and large businesses (Petersen \& Rajan, 1997; Demirguc-Kunt \& Maksimovic, 2002). Trade credit attracts even buyers with strong credit rating as it improves their net working capital (Petersen \& Rajan, 1997). Many companies use it to finance their purchases (accounts payable) and at the same time to provide financing to their clients (accounts receivable). Trade credit increases free cash flow and thereby improves a company's ability to provide customers with further payments facilities. This finding explains why there is a positive correlation between upstream and downstream credit periods of the company (Fabbri \& Klapper, 2009).

Trade credit is the contractual payment term between the customer and the supplier. It offers suppliers a means of discrimination besides the price. Prior research has shown that trade credits may also influence the ordering behavior of the buyer. Fabbri and Klapper (2009) showed that businesses are likely to offer commercial credit as a competitive gesture. Customer tends to order larger quantities if the supplier grants a trade credit (Heydari et al., 2017).

The company may in some cases extend or defer accounts payable beyond the due date. Some suppliers allowed the customer not to pay on the deadline, provided to apply penalties on the invoice amount. Luo and Shang (2013) analysed the behaviour of companies that use trade credit. They showed that the company may choose not to pay the bills at the due date if its current level of working capital is low and the stock-out penalty is higher than the payment default penalty. This explains why payment defaults are frequently observed in practice as the penalty cost of the default is usually low. In addition, a discount for early payment can be applied to encourage customers to pay before the deadline (Brealey et al., 2011).

Gupta and Dutta (2011) considered all of these contractual clauses. The amount to pay for each invoice differs according to three possible scenarios: (i) the invoice is paid at a discount before or at the discount period; (ii) the invoice is paid at its real value after the discount date, but before or at the payment deadline; and (iii) the invoice is paid with a penalty that depends on the time elapsed after the payment deadline. The authors developed a mathematical model that aims to find an optimal schedule for payments and does not consider the corresponding physical flows. 


\subsection{Overall comments}

Recent studies have emphasized the negative outcomes of neglecting the financial flows and the necessity to coordinate operational and financial decisions. The joint planning of physical and financial flows enables companies to avoid insolvencies and infeasible plans (Guillén et al., 2006). Nevertheless, very limited research has been developed to integrate financial aspects in the supply chain management. In addition, existing studies that coordinate operations and financial planning do not include solutions such as supply contracts and commercial financing. To the best of our knowledge, existing studies do not take into account inter-firm contracts and interests due to late payments. We believe that these issues affect working capital and can lead to decision changes. This paper proposes to complete the works that integrate financial flows with physical flows in the field of supply chain management. Hence, there is a need to develop a new model that incorporates the following elements:

-Consideration of lead time constraints related to decision-making, which limits business reactivity and affect working capital requirements,

-Supply management in relation to supplier's capabilities of reaction,

-Payment scheduling taking into account penalties.

In the present work, we consider a type of supply contract between the producer and the supplier that states the demand terms such as its frozen and flexible horizons and the possible degree of flexibility.

A number of papers dealing with the joint management of physical and financial planning recognised the effect of uncertainties on financial flows. According to Gupta (2011) "Future cash inflows and outflows are mostly unknown, because such inflows and outflows depend on movement of goods which again depends on market demand." Studies dealing with uncertainties in the supply chain often use stochastic modelling (Puigjaner \& Laienz, 2008; Sodhi \& Tang, 2009; Hahn \& Kuhn, 2012; Nickel et al., 2012; Longinidis \& Georgiadis, 2011; Longinidis et al., 2015). Our approach is based on a rolling horizon planning process, which enables us to integrate uncertainties, analyse the inter-company interactions and integrate the degree of responsiveness defined jointly by the company and its suppliers. A rolling horizon process thereby guarantees efficient implementation of the contracts commitments.

Our main contribution is to highlight the effect of lead times as a logistic bullwhip not only on the physical flows, but also on cash flow and working capital requirements.

\section{Problem statement and assumptions}

In this paper, we develop a mathematical formulation (presented in detail in Section 4) considering the structure of a supply chain that is composed of four actors: manufacturer (producer of final product), a subcontractor, customers and suppliers. Fig. 1 presents the flow exchanges between the supply chain actors. This study is focused on the production planning of the manufacturer. The implemented approach takes into account the multi-periodic planning of production, shipment and procurement. The proposed formulation combines a cash flow management model with site planning during the tactical planning process and takes into account budgetary constraints and demand uncertainties.

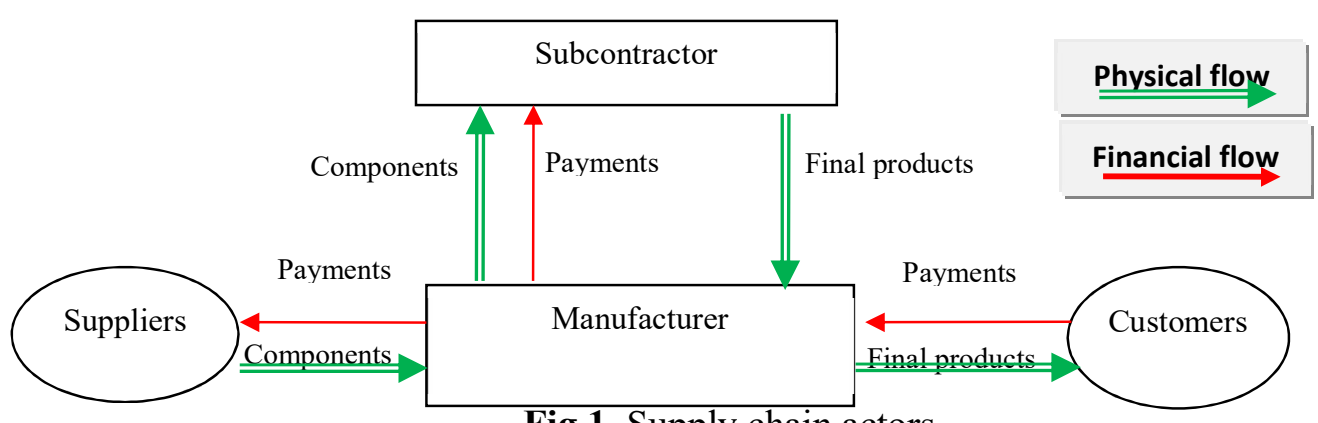

Fig.1. Supply chain actors 
The decisions considered in this tactical model can be grouped into two classes: operational decisions and financial decisions. Operational decisions include quantity to purchase, planning of production, inventory and shipment. Financial decisions concern the choice of financing sources and cash budgeting. Depending on the available cash, the firm may choose between bank financing, trade credits or factoring to finance its activities. Moreover, financial planning includes a payment schedule.

The manufacturer can increase its production capacity through additional capacities or subcontracting. If a part of the orders is subcontracted, the manufacturer provides his/her subcontractor with the necessary components for the manufacture of the desired units. Additional capacities cannot exceed a maximum threshold defined for each period. The following assumptions are made to establish the supply chain tactical planning model:

-Inventory, backorder, purchase and extra-hours costs vary over time.

-Unsatisfied orders are carried forward to future periods. Delays in delivery are penalized in terms of cost, but demands are honoured.

-The company allows a fixed payment delay to its customers.

-The company can decide the payment date of its suppliers without exceeding a maximum deadline.

-The company may opt for factoring services. Factoring is the selling of accounts receivable to a factor, typically a bank or a specialized credit institution, in exchange for immediate cash.

- The company has a current account to improve its day-to-day cash flow. It has access to short-term debt, similar to a conventional open line of credit, to cover short-term cash shortfalls. The company can use this loan up to a maximum allowable debt.

-The long-term assets and long-term liabilities of the company will not vary during the planning horizon.

The target is to obtain a production plan that allows the producer to meet his customers' demands at minimal operational and financial costs while respecting the restrictions of the working capital requirement.

In order to cope with demand uncertainties, we develop an iterative planning procedure within a rolling horizon process, where periodic updates of the production plan are made following the latest demand information available. This dynamic process constitutes a way of reacting to forecasts errors (Lalami $e t$ al., 2017). Therefore, at each iteration over the planning horizon, data are updated and decisions are adjusted to mitigate the impacts of fluctuations.

In a rolling horizon process, the decisions are revisited with a fixed periodicity, which is equal to the time between two successive iterations. However, many research works point out that the implementation of this planning process provokes a problem of nervousness and instability of the decisions (Lin \& Uzsoy, 2016). The introduction of a frozen horizon is one of the frequently used methods for reducing the planning instability. A common practice is to ensure a stabilization by prohibiting any change in the decisions that have been made for prespecified periods situated at the beginning of the planning horizon. These periods constitute the so-called "frozen horizon". This means that when the planning horizon is rolled forward, decisions that belong to the frozen horizon have to be implemented and possible changes concern only later decisions. The length of the frozen horizon limits the responsiveness of the chain to changes. Amrani-Zouggar et al. (20012), among many others works, showed that the costs of the supply chain increase as the length of the frozen horizon increases. Logically, the length of the frozen horizon must take into account the anticipation delays of decisions. The anticipation delay inherent in decision-making is a source of inertia and limits the responsiveness of the system to adapt to changes. Indeed, a decision characterized by an anticipation delay of $A D$ periods must be taken at the latest in the period $\tau$ with $\tau \leq t-A D$ to be applicable at period t (Galasso et al., 2009). Therefore, the length of the frozen horizon is not chosen freely. A frequent practice consists in choosing a frozen horizon at least 
equal to the maximum among the anticipation delays of all decisions, to guarantee the implementation of the decisions.

In a real industrial context, some decisions need less anticipation delays than others do. Thus, to have a greater margin of responsiveness, we choose a frozen horizon adapted to each decision, which is equal to its anticipation period.

\section{Dynamic planning model}

We divide the whole planning horizon into periods $t(t \in\{1 \ldots T H\})$. At each iteration, only a part of the planning horizon is modelled. This rolling planning relies on solving a sequence of sub-problems over equal time horizon $T(T<T H)$. We denote by $\varphi^{i}$ the starting period of the rolling horizon that is considered at the planning step $i$. We let $\delta$ refer to the number of periods by which the planning horizon is rolled forward after each iteration. Hence, for each step $i$, the starting period is $\varphi^{i}=(i-1) \cdot \delta+1$.

The first planning step $(i=1)$ is performed at the horizon $H P^{l}$ that starts at the period $t=1$, with $H P^{l}=$ $\{1,2 \ldots T\}$. At the period $t=1+\delta$, we proceed to the second planning step $(i=2)$ that is performed at the updated horizon $H P^{2}=\{1+\delta, 2+\delta \ldots T+\delta\}$. The second iteration takes into account the previous planning decisions. The frozen decisions at the iteration $i=1$ are not changed by the second planning iteration. In general, at each step $i$, new planning is performed over a time horizon $H P^{i}=\left[\varphi^{i}, \varphi^{i}+1, \varphi^{i}+2\right.$, $\left.\ldots, \varphi^{i}+T-1\right]$. This procedure is then repeated for $i=3, i=4, i=5$, etc., until the whole planning horizon is covered.

The following model corresponds to the scheduling problem that will be solved at each planning iteration $i$, over the planning horizon $H P^{i}$. In this model, the demand is assumed to be known throughout the planning horizon and it is updated at each planning iteration. Below, we detail the parameters, the decision variables and the constraints of the model.

\subsection{Notation}

Sets and parameters of the rolling horizon planning

$P$ : set of finished products, indexed by $p$

$C$ : set of components (raw materials), indexed by $c$

$F$ : set of suppliers, indexed by $f$

$J$ : set of customers, indexed by $j$

$T$ : number of periods in the planning horizon

$i$ : iteration number of the planning ( $i$ is the planning step)

$\delta$ : planning periodicity (number of periods between two successive planning iterations)

$\varphi^{i}$ : index of the first elementary period at each planning step $i ; \varphi^{i}=(i-1) \delta+1$

$P H^{i}$ : planning horizon at planning step $i ; P H^{i}=\left\{\varphi^{i}, \varphi^{i}+1, \ldots, \varphi^{i}+T-1\right\}$

$K$ : set of all decisions that must be sufficiently anticipated before being implemented, indexed by $k$. $K=$ $\{l, s, b\} \cup F$ representing the decisions associated with internal production $(l)$, subcontracting $(s)$, allocation of additional capacities $(b)$ and purchasing components from suppliers $(F)$.

$F H^{k}$ : length of the frozen horizon associated with the decision $k$ (equal to the anticipation delay of the decision)

$F L H$ : length of the flexible horizon authorized by the supplier $f$

$\beta_{f} \%$ : flexibility rate offered by the supplier f during the flexible horizon

$\underline{\text { Static data (independent of the planning step } i \text { ) }}$

$D F_{p}$ : lead time for obtaining final product $p$ using internal production 
$D S_{p}$ : lead time for obtaining final product $p$ using sub-contracting

$m_{p}$ : unit processing time of final product $p$

$C A P_{t}$ : production capacity in period $t$ (in hours)

$B_{\text {max }}$ : maximum number of overtime hours

$S M_{p t}$ : the maximum production volume of the product $p$ from subcontracting in period $t$

$\alpha_{p c}$ : bill of material coefficient linking final product $p$ and component $c$

$v_{p}$ : space needed to store a unit of product $p$

$\omega_{c}$ : space needed to store a unit of component $c$

$C S P_{t:}$ warehouse storage capacity of finished goods at period $t$

$C S C_{t}$ : warehouse storage capacity of the component at period $t$

$P V_{p l t}$ : unit selling price of the product $p$ to the customer $l$ at period $t$

$c a_{c f t}$ : cost of component $c$ provided by supplier $f$ in period $t$. It includes the purchase and transportation costs charged to the firm.

$P s_{p t}$ : unit inventory cost of product $p$ in period $t$

$g_{p t}$ : unit shortage cost of product $p$ in period $t$

$C s_{c t}$ : unit inventory cost of component $c$ in period $t$

$p r_{p t}$ : unit production cost of product $p$ in period $t$

$s t_{p t}$ : unit subcontracting cost of product $p$ in period $t$

$b$ : cost of using an additional hour (overtime)

$d i s_{f}$ : length of the payment discount period authorized by supplier $f$ in number of periods

$d_{f}$ : payment delay authorized by supplier $f$ in number of periods

$d_{f}^{\text {max }}$ : prescription period of payment imposed by supplier $f$ in number of periods

$\tau d_{f}$. discount rate offered by supplier $f$

$\tau p_{f}$. penalty rate applied by supplier $f$ per period if an invoice is not paid on or before the payment delay.

$d c$ : customer payment delay in number of periods

$r_{e}$ : the interest rate for depositing money

$r_{c}$ : the interest rate for the short-term loan

MaxDett: maximum credit line

MinCash: minimum cash flow imposed by the bank

$\mu$ : percentage of value of accounts receivable billed to recover

$\operatorname{val}_{p t}{ }^{F}$ : value of the finished product $p$ at the period $t$

$v a l_{c t}^{I}$ : value of component $c$ at period $t$

Dynamic data (updated for each planning step $i$ )

$D_{p j t}^{i}$ : demand for product $p$ from customer $j$ in period $t$

$\underline{\text { Decision variables defined at step } i}$

$L_{p t}^{i}$ : quantity of product $p$ to be produced during period $t$ 
$S_{p t}^{i}$ : quantity of product $p$ subcontracted during period $t$

$B_{t}^{i}$ : extra-hours used in period $t$

$I_{p t}^{i}$ : inventory levels of final products $p$ at the end of period $t$

$V_{p j t}^{i}$ : quantity of the product $p$ sold to the customer $j$ at the period $t$

$G_{p j t}^{i}$ : backorder levels at the end of period $t$ for final products $p$ relative to customer $j$

$E_{c t}^{i}$ : inventory levels of component $c$ at the end of period $t$

$A f^{t} t t^{\prime}$ : the amount of receivables factored in period $t^{\prime}$ for sales in period $t$

$\operatorname{Com}_{c f t}$ : quantity of component $c$ ordered from supplier $f$ to be available in period $t$

$F v^{i} f t$ value of deliveries for the period $t$ from supplier $f$

$P a y_{f t t}{ }^{\prime}$ : amount paid for deliveries of period $t$ from supplier $f$ at period $t^{\prime}$

$E P^{i}$ : amount borrowed from the line of credit in period $t$

$R P^{i}{ }_{t}$ : amount repaid of the credit line in period $t$

Cred ${ }^{i}$ : level of short-term debt during the period $t$

$\operatorname{cash}^{i}$ : cash flow at the end of the period $t$

$\triangle C F^{i}$ : change in net cash flow

$\triangle W C R^{i}$ : change in working capital requirement

$\triangle G N W C^{i}$ : change in global net working capital

\subsection{Planning model $M^{i}$}

The model $M^{i}$ is solved at iteration $i$ over the planning horizon $P H^{i}$. It includes the concepts previously outlined. Form one iteration to another, the model is executed while integrating the previous frozen decisions and the periodic update of demand information.

\subsubsection{Logistic constraints}

The constraints related to physical flows are explained in this subsection. Constraint (1) is associated with the balance of product flows.

$$
I_{p t}^{i}=I_{p t-1}^{i}+L_{p\left(t-D F_{p}\right)}^{i}+S_{p\left(t-D S_{p}\right)}^{i}-\sum_{j \in J} V_{p j t}^{i} \quad p \in P, t \in P H^{i}
$$

Constraint (2) states that the shortage should be equal to the difference between the demand of customers and the delivery of the products to these customers.

$$
G_{p j t}^{i}=G_{p j t-1}^{i}+D_{p j t}^{i}-V_{p j t}^{i} \quad p \in P, j \in J, t \in P H^{i}
$$

The constraints (3)-(5) ensure the respect of the production capacity.

$$
\begin{aligned}
& \sum_{p \in P} m_{p} L_{p, t}^{i} \leq C A P_{t}+B_{t}^{i} \quad t \in P H^{i} \\
& B_{t}^{i} \leq B_{\max } \quad t \in P H^{i} \\
& S_{p t}^{i} \leq S M_{p t} \quad p \in P, t \in P H^{i}
\end{aligned}
$$


Constraint (6) ensures that production plant receives enough components in order to produce the decided quantity of finished products.

$$
E_{c t}^{i}=E_{c t-1}^{i}+\sum_{f \in F} \operatorname{Com}_{c f t}^{i}-\sum_{p \in P} \alpha_{p c}\left(L_{p t}^{i}+S_{p t}^{i}\right) . \quad c \in C, t \in P H^{i}
$$

Constraints (7)-(8) ensure the respect of the storage capacities.

$$
\begin{array}{ll}
\sum_{p \in P} v_{p} I_{p t}^{i} \leq C S P_{t} . & p \in P, t \in P H^{i} \\
\sum_{c \in C} \omega_{c} E_{c t}^{i} \leq C S C_{t} & t \in P H^{i}
\end{array}
$$

\subsubsection{Integration constraints}

The integration between physical and financial flows is based on the gain that is generated from the products' sales and the expenses inherent by their manufacture.

The accounts receivable in each period $t$ is calculated using Eq. (9).

$$
A R_{t}^{i}=\sum_{j \in J} \sum_{p \in P} P V_{p j t} V_{p j t}^{i} \quad t \in P H^{i}
$$

Eq. (10) expresses the costs related to the production activities in each period $t$. The cost of production takes into account the charges coming from holding inventories, production, subcontracting, additional capacity and shortage.

$$
C T_{t}^{i}=\sum_{p \in P} p r_{p t} L_{p t}^{i}+\sum_{p \in P} s t_{p t} S_{p t}^{i}+\sum_{p \in P} \sum_{j \in J} g_{p t} G_{p j t}+\sum_{p \in P} P s_{p t} I_{p t}^{i}+\sum_{c \in C} C s_{c t} E_{c t}^{i}+b B_{t}^{i} t \in P H^{i}
$$

An invoice is generated by supplier $f$ after shipping products to the manufacturer. Eq. (11) expresses the value of the invoice for each supplier $f$ at period $t$.

$$
F v_{f t}^{i}=\sum_{c \in C} c a_{c f t} \operatorname{Com}_{c f t}^{i} \quad f \in F, t \in P H^{i}
$$

\subsubsection{Cash flow budgeting model}

A budgeting system makes it possible to correlate the incoming and outgoing of financial flows.

\section{Accounts Receivable Management}

Factoring is a traditional type of financing that attempts to increase liquidity and speed up access to cash for companies who do not wish to wait for the due dates of payment by customers (Sodhi and Tang, 2012). The company sells its invoices to a factoring company (called factor) at a discount, amounting to interest plus service fees and receives cash immediately (Sopranzetti, 1998; Soufani, 2002; Klapper, 2006; Yang \& Birge, 2013; Lin et al., 2018). Klapper (2006) carried out an econometric analysis of the benefit of factoring as a means of providing more funds for small and medium enterprises. Thus, by selling its debts to another organization, the company immediately receives a portion (usually $80 \%$ ) of the amount of the receivables transferred. 
The variable $A f_{t t^{\prime}}$ represents the amount of customer receivable factored in period $t^{\prime}$ for sales made in period $t$. It is assumed that receivables on sales in any period are paid with a delay equal to $d_{c}$ periods.

$$
\sum_{t^{\prime}=t}^{t+d c-1} A f_{t^{\prime}}^{i} \leq A R_{t}^{i} \quad t \in P H^{i}
$$

The amount to be received in each period is equal to the amount of accounts receivable incurred in period $t-d_{c}$ matured in period $t$, minus the amount of these accounts factored in periods $t-d_{c}$ to $t$ - 1 , plus the amount factored in the current period on accounts receivable incurred in periods from $t-d_{c}+1$ to $t$.

$$
S R_{t}^{i}=A R_{t-d c}^{i}-\sum_{t^{\prime}=t-d c}^{t-1} A f_{(t-d c) t^{\prime}}^{i}+\sum_{t^{\prime}=t-d c+1}^{t} \mu A f_{t^{\prime} t}^{i} \quad t \in P H^{i}
$$

\section{Accounts Payable Management}

The supplier generates an invoice immediately when the components are shipped to the manufacturer. The model aims to find the optimal payment date for each invoice. The amount to pay for each invoice differs according to three possible scenarios, as follows:

$$
P a y_{f t t^{\prime}}= \begin{cases}F v_{f t}\left(1-\tau d_{f}\right) & \text { si } t \leq t^{\prime} \leq t+d i s_{f} \\ F v_{f t} & \text { si } t+d i s_{f}<t^{\prime} \leq t+d_{f} \\ F v_{f t}\left(1+\tau p_{f}\right)^{t^{\prime}-\left(t+d_{f}\right)} & \text { si } t+d_{f}<t^{\prime} \leq t+d_{f}^{\max }\end{cases}
$$

where $P_{a y} y_{f t}$ ' denotes the amount paid in period $t$ ' for the invoice received at time $t$ from the supplier $f$. $F v_{f t}$ is the face value of the invoice received at time $t$ from the supplier $f . \tau d_{f}$ is the discount rate which is applied if the invoice is paid before the payment discount period $d i s f . \tau p_{f}$ is the penalty rate applied if the payment for the invoice is not made within a due date $d_{f}$ and the penalty starts accruing daily from the due date $d_{f}$ until the limitation period $d_{f}^{\max }$. The invoice payment should be made before the prescription period $d_{f}^{\max }$.

In a similar way, the link between the value of the invoice $\left(F v_{f t}\right)$ and the value to be paid $\left(\right.$ Pay $\left._{f t}{ }^{\prime}\right)$ can be rewritten as follows:

$$
F v_{f t}=\left\{\begin{array}{lr}
\operatorname{Pay}_{f t t^{\prime}} \frac{1}{\left(1-\tau d_{f}\right)} & \text { si } t \leq t^{\prime} \leq t+d i s_{f} \\
\operatorname{Pay}_{f t t^{\prime}} & \text { si } t+d i s_{f}<t^{\prime} \leq t+d_{f} \\
\operatorname{Pay}_{f t t^{\prime}} \frac{1}{\left(1+\tau p_{f}\right)^{t^{\prime}-\left(t+d_{f}\right)}} & \text { si } t+d_{f}<t^{\prime} \leq t+d_{f}^{\max }
\end{array}\right.
$$

Thus, the model may choose to anticipate or delay payments to suppliers. The contractual terms on accounts payable (discount, net and penalty) must be applied as guaranteed by constraints (14)-(15). These constraints relate the payment executed in period t' on accounts payable incurred in $t$ according to the delay provided by each supplier.

Constraint (14) states that each invoice should be paid before the deadline $\left(d_{f}^{\max }\right)$.

$$
\begin{aligned}
& \sum_{t^{\prime}=t}^{t+d i s_{f}} \frac{1}{\left(1-\imath d_{f}\right)} P a y_{f t t^{\prime}}^{i}+\sum_{t^{\prime}=t+d i s_{f}+1}^{t+d_{f}} P a y_{f t t^{\prime}}^{i}+\sum_{t^{\prime}=t+d_{f}+1}^{t+d_{f}^{\max }} \frac{1}{\left(1+\imath p_{f}\right)^{t^{\prime}-\left(t+d_{f}\right)}} P a y_{f t t^{\prime}}^{i}=F v_{f t}^{i} \\
& f \in F, t \leq \varphi^{i}+T-1-d_{f}^{\max }
\end{aligned}
$$

Settlement of the invoice is not required for accounts that are not matured before the end of the planning period (15). 


$$
\begin{aligned}
& \sum_{t^{\prime}=t}^{t+d i s_{f}} \frac{1}{\left(1-\imath d_{f}\right)} P a y_{f f t^{\prime}}^{i}+\sum_{t^{\prime}=t+d i s_{f}+1}^{t+d_{f}} P a y_{f f t^{\prime}}^{i}+\sum_{t^{\prime}=t+d_{f}+1}^{t+d_{f}^{\max }} \frac{1}{\left(1+\imath p_{f}\right)^{t^{\prime}-\left(t+d_{f}\right)}} P a y_{f t t^{\prime}}^{i} \leq F v_{f t}^{i} \\
& f \in F, t>\varphi^{i}+T-1-d_{f}^{\max }
\end{aligned}
$$

Constraint (16) calculates the amount paid for the accounts payable at period $t$.

$$
S P_{t}^{i}=\sum_{f \in F} \sum_{t^{\prime} \in P H^{i}} P a y_{f t^{\prime} t} \quad t \in P H^{i}
$$

The constraint (17) states that the total debt in each period is a function of the debt in the previous period, the money borrowed from the line of credit, the money repaid to the line of credit, and the costs of interest.

$$
\text { Cred }_{t}^{i}=\left(1+r_{c}\right) \text { Cred }_{t-1}^{i}+E P_{t}^{i}-R P_{t}^{i} . \quad t \in P H^{i}
$$

The bank loan is another source of financing, obtained at the beginning of the period with an interest rate $\left(r_{c}\right)$, which is supposed to be already negotiated with the bank. In this case, the bank requires a minimum of cash (MinCash), usually as a percentage of the amount borrowed, and limits the company to an open line of credit with a ceiling set in advance (MaxCrd). Eqs. (18-19) show the minimum and maximum credit under an agreement with the bank.

$$
\begin{array}{cc}
\text { Cred }_{t}^{i} \leq \text { MaxDett } & t \in P H^{i} \\
\text { cash }_{t}^{i} \geq \text { MinCash } & t \in P H^{i}
\end{array}
$$

\section{$\underline{\text { Cash management }}$}

The cash at the end of each period represents the difference between cash outflows and inflows as given in constraint (20). Cash at period $t$ is a function of the cash at period $t-1$, cash borrowed or repaid to credit line, receivable from customers, the amount payable to suppliers and production costs charged to the same period $t$.

$$
\operatorname{cash}_{t}^{i}=\left(1+r_{e}\right) \operatorname{cash}_{t-1}^{i}+E P_{t}^{i}-R P_{t}^{i}+S R_{t}^{i}-S P_{t}^{i}-C T_{t}^{i} \quad t \in P H^{i}
$$

\section{$\underline{\text { Working capital management }}$}

Global Net Working Capital $(G N W C)$ is the sum of money that is constantly available to cover current expenses. Between delivery of products to customers and collection of sales, there is a certain amount of time. During this period, the company always needs cash. Having a working capital allows for meeting all the expenses while waiting for receipts. The change in $G N W C$ can be computed as the sum of the net cash flow variation $(\triangle C F)$ and the variation in the working capital requirement $(\triangle W C R)$.

Eq. (21) indicates that the variation in net cash is equal to the difference between active cash (available cash) and bank credit at the end of the first period and the last period.

$$
\Delta C F^{i}=\left(\operatorname{cash}_{\varphi^{i}+T-1}^{i}-\text { Cred }_{\varphi^{i}+T-1}^{i}\right)-\left(\text { cash }_{0}-\text { Cred }_{0}\right) .
$$

The change in the $W C R$ is equal to the $W C R$ in the last period minus the $W C R$ in the first period.

$$
\begin{aligned}
& \Delta W C R^{i}=\left(\sum_{t=\varphi^{i}+T-d c}^{\varphi^{i}+T-1} A R_{t}^{i}-\sum_{t=\varphi^{i}+T-d c}^{\varphi^{i}+T-1} \sum_{t^{\prime}=\varphi^{i}+T-d c}^{\varphi^{i}+T-1} A f_{t t^{i}}^{i}+\sum_{p \in P} v a l_{p T}^{F} I_{p T}^{i}+\sum_{c \in C} v a l_{c T}^{I} E_{c T}^{i}-\sum_{f \in F} \sum_{t=\varphi^{i}}^{\varphi^{i}+T-1} F v_{f t}^{i}\right. \\
& \left.+\sum_{f \in F} \sum_{t=\varphi^{i}}^{\varphi^{i}+T-1} \sum_{t^{i}=\varphi^{i}}^{\varphi^{i}+T-1} P a y_{f t^{\prime}}^{i}\right)-\left(A R_{0}+\sum_{p \in P} v a l_{p 0}^{F} I_{p 0}+\sum_{c \in C} v a l_{c 0}^{I} E_{c 0}\right)
\end{aligned}
$$




\subsubsection{Freezing decisions according to their anticipation delay}

Constraints (23)-(25) formalize the consistency of decisions between two successive planning iterations (i) and $(i+1)$. The application of these constraints is limited to the respective frozen horizons of each decision. There is equality between the values engaged in anticipation and the values that will be implemented for all decisions (internal production, subcontracting and allocation of additional capacities).

$$
\begin{array}{ll}
L_{p t}^{i}=L_{p t}^{i-1} & p \in P, t \in\left\{\varphi^{i}, \ldots, \varphi^{i}+F H^{l}-\delta-1\right\} \\
S_{p t}^{i}=S_{p t}^{i-1} & p \in P, t \in\left\{\varphi^{i}, \ldots, \varphi^{i}+F H^{s}-\delta-1\right\} \\
B_{t}^{i}=B_{t}^{i-1} & t \in\left\{\varphi^{i}, \ldots, \varphi^{i}+F H^{b}-\delta-1\right\}
\end{array}
$$

\subsubsection{Introduction of supply contractual terms}

In this subsection, we will introduce the contractual constraints related to the rolling horizon flexibility (RHF) contracts. When a frozen horizon is negotiated through supply contract between two partners, the values of purchasing quantities over the frozen horizon are committed and cannot be modified by subsequent plans.

Wherever possible, the supplier has an interest in increasing his reactivity to be more competitive and increase his turnover. However, it is not always easy for the supplier to reduce his anticipation delay since it is imposed by the constraints related to its production system. In order to provide more flexibility, the supplier may divide the anticipation delay into two parts. Then, a flexible horizon is defined to replace a part of the frozen horizon. Over the flexible horizon, the supplier allows for a rate of flexibility ( $\left.\omega_{f} \%\right)$ to adjust the order between two planning steps. Therefore, the buyer (the manufacturer, in our case) is allowed to modify his purchase within limits. The flexibility bounds are $+\omega_{f} \%$ and $-\omega_{f} \%$ of the previous order. Inequality (27) expresses, for each supplier, the permitted flexibility. At each planning step $i$, for any period $t$ belonging to the flexible horizon, the order must vary between two limit values that correspond to plus or minus $\omega_{f} \%$ of the preceding order.

$$
\begin{aligned}
& \operatorname{Com}_{c f t}^{i}=\operatorname{Com}_{c f t}^{i-1} \quad c \in C ; f \in F ; t \in\left\{\varphi^{i}, \ldots, \varphi^{i}+F H^{f}-\delta-1\right\} \\
& \left(1-\omega_{f} \%\right) \operatorname{Com}_{c f t}^{i-1} \leq \operatorname{Com}_{c f t}^{i} \leq\left(1-\omega_{f} \%\right) \operatorname{Com}_{c f t}^{i-1} \\
& \forall i ; \forall c \in C, \forall f \in F, \forall t \in\left\{\varphi^{i}+F H F^{f}-1, \ldots, \varphi^{i}+F L H^{f}-1\right\}
\end{aligned}
$$

Finally, the resulting MILP model can be stated as follows:

$\max \Delta G N W C^{i}=\Delta C F^{i}+\Delta W C R^{i}$

subject to constraints: Eqs. (1)- (27)

\section{Experimentation and analysis}

Our experiments are performed based on a case study that is specifically generated to illustrate the applicability of the proposed model and to show how the latter can be used by managers as a decision aid tool. The experiments are guided by the following goals: Evaluate the performance of the proposed approach and analyze the impact of supplier's flexibility.

We used the commercial optimization software Cplex 12.6 to solve the model. Experiments are conducted on an Intel Core i5 PC with a clock frequency of $2.27 \mathrm{Ghz}$.

\subsection{Description of the case study}

The study framework is a hypothetical case of a production site. The complexity of the problem is reduced to avoid a useless explosion of the data and the difficulty to analyse the results of 
experimentations. We consider the case of an assembly plant with two suppliers, one customer and a single finished product over a horizon of 24 periods. For ease of presentation, the bill of material of the finished product is deliberately chosen to be simple: it includes only two components. Here, the finished product $P$ requires two components of type 1 " $C 1$ " and one component of type 2 " $C 2$ ".

We adopted a global horizon $T H$ of 24 periods. Over this horizon, customer demand is expected to evolve during different planning stages. In a rolling horizon planning, it is necessary, as time progresses, to be able to generate new orders, to complete the $P H$ planning horizon. At each planning step, the demands that belong to the first periods of the horizon become available. We simulate this process by replacing the demand forecast with a firm demand randomly generated according to a uniform distribution over an interval corresponding to plus and minus $30 \%$ of the demand forecast. The periodicity of the planning $(\delta)$ is fixed to 2 periods. We establish, at the beginning of each stage of replanning, an update of the demand forecast without changing the orders that belong to the first four periods constituting the frozen horizon of demand. The delays and costs associated with production decisions (internal or subcontracted) are listed in Table 1. These data are inspired from the case studies presented in Gallasso et al. (2009).

The producer should choose between two suppliers who are distinguished by the tariffs they practice, their lead times and their payment delays. The second supplier is more expensive, but has a shorter anticipation delay and allows for more flexibility in payment. The first supplier allows for a payment delay of 28 days. The second supplier encourages advance payments by a discount on payments settled in the first week. After the deadline ( 28 days), it allows for an additional delay of 28 days, but a penalty rate of $0.02 \%$ is applied for each day of delay. Table 2 summarizes the characteristics of the suppliers.

\section{Table 1}

Production decisions characteristics

\begin{tabular}{llll}
\hline Decision & Anticipation delay (days) & Lead-time (days) & Unit cost (um) \\
\hline Internal Production & 0 & 0 & 5 \\
Subcontracting & 2 & 2 & 30 \\
Extra-hours & 1 & 0 & 55 \\
\hline
\end{tabular}

\section{Table 2}

Suppliers characteristics

\begin{tabular}{lllll}
\hline Procurement & Unit price (um) $C 1$ & Unit price (um) $C 2$ & Anticipation delay (days) & Payment delay (days) \\
\hline Supplier 1 & 1.2 & 0.6 & 2 & 28 \\
Supplier 2 & 2 & 1 & 6 & 56 \\
\hline
\end{tabular}

Concerning financial parameters, the initial cash is $1000 \mathrm{um}$. The bank offers an open line of credit with an annual interest rate of $10 \%$. This company uses a current account to improve its cash flow and facilitate cash inflows and outflows operations with an annual interest rate equal to $3 \%$. The company recovers $80 \%$ of the amount of invoices.

\subsection{Design of the experiments}

Planning decisions are built progressively at each planning step $i$ by solving the model $M^{i}$. At the beginning of each iteration $i$, the set of initial conditions (work-in-progress, inventory levels, pending invoices, etc.) and frozen decisions are reported from the previous iteration $i-1$.

At the end of the procedure, the frozen decisions are collected to build the entire plan, denoted by $P^{i}$. In our different simulations, the iterations for solving the planning model will take place until the frozen decisions cover the entire simulation horizon. The implemented plan $P^{i}$ is therefore the concatenation of the decisions that are frozen at each new planning step.

It is possible to obtain an "ideal plan" denoted by IP, assuming that the real demand over the simulation horizon is perfectly known at the first planning step. The ideal plan is then obtained in a single step by 
solving the model $M^{0}$ over the planning horizon $H P^{0}=T H$. This assumption allows for the elaboration of an optimal plan resulting from a perfect knowledge of the demand. This plan is used later as a reference. Thus, the plans resulting from the dynamic planning process for different settings will be compared to this reference plan.

Table 3 presents the key performance indicators that we propose to compare the different cases.

Table 3

Key performance indicators (KPI)

\begin{tabular}{|c|c|c|}
\hline Axes & Indicators & Indicator description \\
\hline Reliability & Service rate $\left(T_{s}\right)$ & $\begin{array}{l}\text { Describes the average ability of an actor to satisfy customer } \\
\text { demand } D_{p, t} \text { excluding the delivered quantities } L_{p, t} \text { to fill a } \\
\text { past backorder } R_{p, t}\end{array}$ \\
\hline Reactivity & $\begin{array}{l}\text { Index of depth of shortage }\left(I_{p r}\right) \\
\text { Index of width of shortage }\left(I_{a m}\right)\end{array}$ & $\begin{array}{l}\text { Total number of periods in which shortage occurs } \\
\text { The largest number of successive periods of shortage to } \\
\text { absorb a demand variation }\end{array}$ \\
\hline Costs & Adaptation cost $\left(C_{a}\right)$ & $\begin{array}{l}\text { Cost of the adaptation efforts made by the actor. It includes } \\
\text { the costs of storage of finished products, component storage, } \\
\text { shortage and extra-hours. } \\
\text { Total cost of the chain }\end{array}$ \\
\hline $\begin{array}{l}\text { Asset } \\
\text { management }\end{array}$ & $\begin{array}{l}\text { Deficit of cash }\left(D_{T}\right) \\
\text { Change in global net working capital } \\
(\triangle G N W C)\end{array}$ & $\begin{array}{l}\text { Total number of periods over which is recorded a cash deficit } \\
\text { Value of objective function }\end{array}$ \\
\hline
\end{tabular}

\subsection{Validation of the proposed approach}

The purpose of this experiment is to highlight the potential of the proposed approach (PA). The results obtained by the traditional approach (TA) are compared to those computed by our approach (PA). A traditional rolling horizon approach applies the same frozen horizon to all decisions to stabilize the supply chain activities. In our approach, we choose a frozen horizon adapted to each decision, which is equal to its anticipation period. The comparison is based on the performance of the global production plan generated by the two approaches. In the example studied in this section, the traditional approach is solved by applying a frozen horizon of six-period length to all decisions, which is the maximum of the anticipation delays of all decisions. Results obtained from applying both approaches are summarized in Table 4. It is obvious that the proposed approach (PA) achieves better results than the traditional approach (TA) and this, for the financial aspect as well as for the service quality aspect. Indeed, PA mitigates demand uncertainties with an adaptation cost that is almost equal to the quarter of the cost generated by TA. Much of this cost difference is due to the backlogs generated by TA as shown in Fig. 2 . This explains why PA achieves a much better average service rate than the traditional method. Furthermore, the results of our approach are close to those obtained by the reference plan IP. The cost difference between our approach and the ideal plan does not exceed 5\%.

\section{Table 4}

Performance of the approach

\begin{tabular}{llll}
\hline & $\begin{array}{l}\text { Traditional Approach } \\
(\mathrm{TA})\end{array}$ & $\begin{array}{l}\text { Proposed Approach } \\
(\mathrm{PA})\end{array}$ & $\begin{array}{l}\text { Ideal Plan (IP) } \\
\text { Service rate }(T s)\end{array}$ \\
Index of depth of shortage $\left(I_{p r}\right)$ & 85.04 & 98.76 & 99.65 \\
Index of width of shortage $\left(I_{a m}\right)$ & 11 & 1 & 1 \\
Cost of adaptation $(C a)$ & 40410 & 1 & 1 \\
Total cost $\left(C_{t}\right)$ & 85660.20 & 9724 & 5628 \\
Occurrence of a cash deficit $\left(D_{t}\right)$ & 4 & 58871.15 & 55899.71 \\
$\triangle C F$ & 76222 & 1 & 1 \\
$\triangle G N W C$ & 104489.172 & 105,650 & 106820 \\
\hline
\end{tabular}




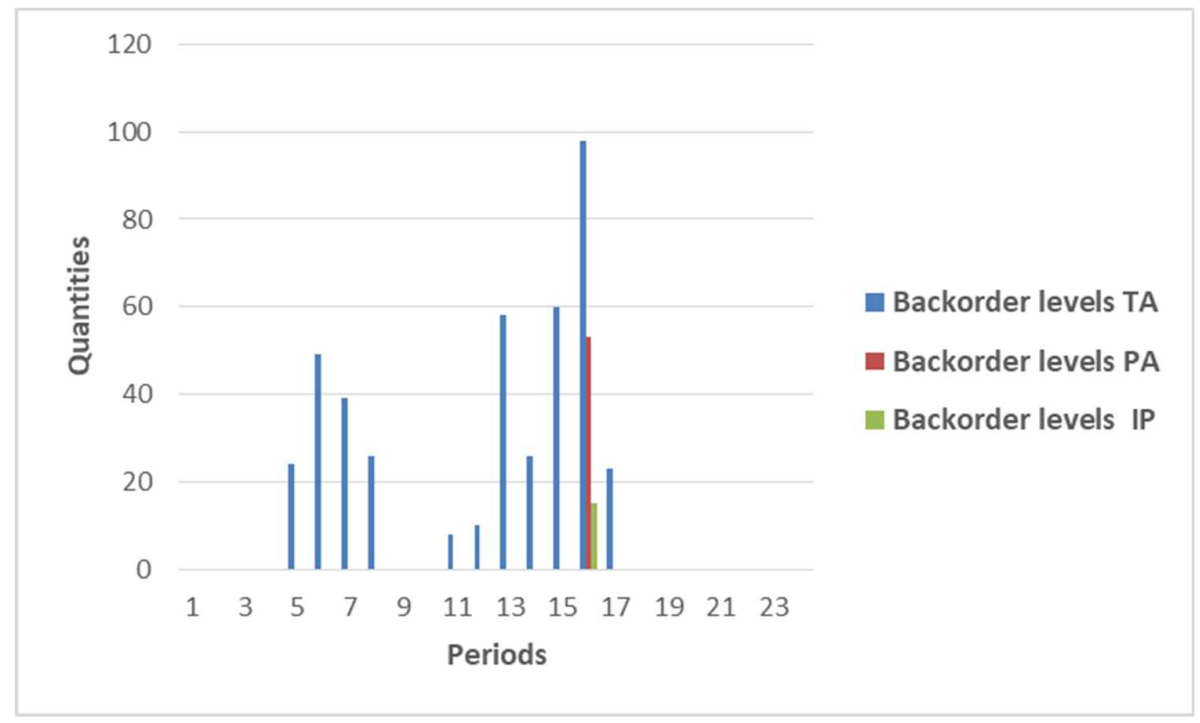

Fig. 2. Evolution of production backlogs over the planning horizon

The performance of the proposed approach is achieved thanks to a better exploitation of the specificities of the anticipation delays of each decision. The anticipation delay related to production and outsourcing makes it possible to better react to variations using a stock of finished product P (Fig.3). On the other hand, the length of the frozen horizon in the traditional approach increased the response time to variations, which is confirmed by a very high index of width of shortage. This observation is also confirmed by Fig. 2 (shortage persists over several periods). We deduce that a fine modelling of the delays characterizing the decision-making process has the benefit of increasing the responsiveness of our approach to demand variations. In addition, knowing precisely the deadlines of each decision gives the possibility to optimize its execution and thereby using it to mitigate the effect of fluctuating demand.

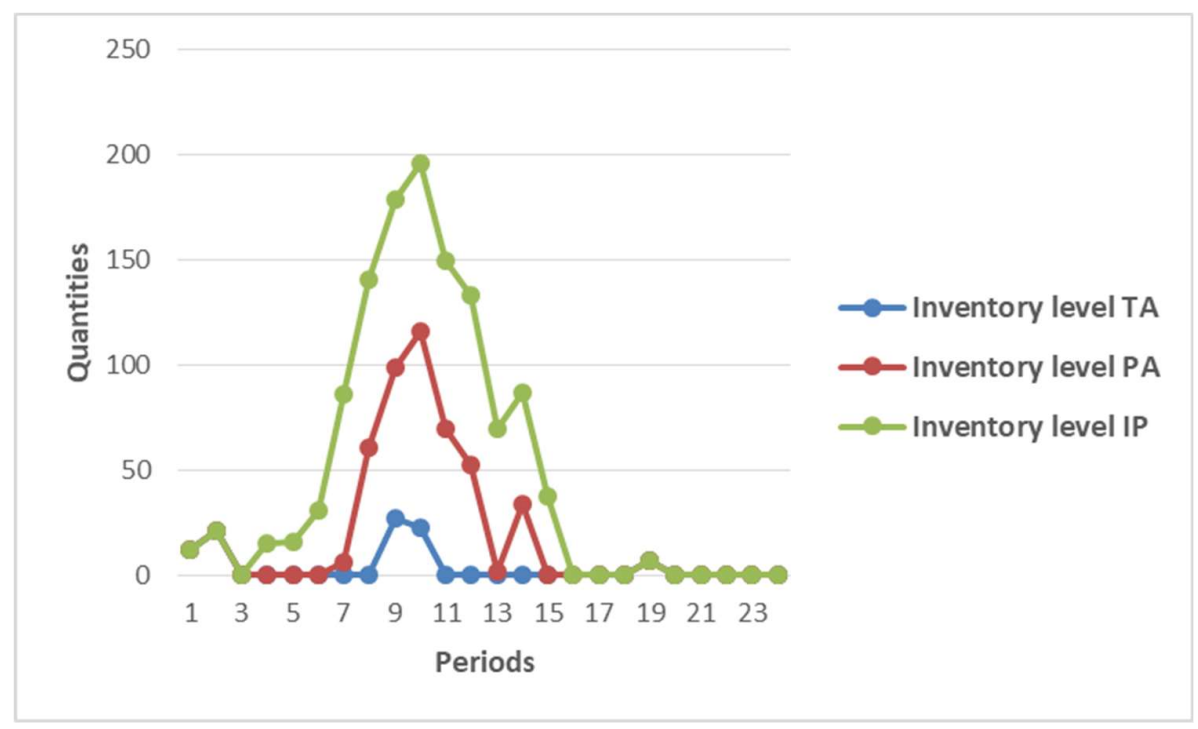

Fig. 3. Evolution of product stocks $P$ over the planning horizon

Our results validate the relevance of including time lags related to decision-making. The increase in the delay to react to uncertainty, due to the mechanism of decision freezing, leads to a low performance in terms of service rate, costs and financial results. 


\subsection{Customer-supplier relationship}

In order to show the relevance of considering supplier reactivity in supply chain optimization, we test different degrees of flexibility for suppliers. The three studied cases are characterized by the responsiveness of suppliers and are ranked in order of increasing reactivity. The delay associated with suppliers are as follows:

Case 1: Suppliers 1 and 2 require a frozen horizon of respectively 6 and 4 periods.

Case 2: Suppliers 1 and 2 require a frozen horizon of respectively 3 and 2 periods. The frozen horizon is completed by a flexible horizon of 3 periods for Supplier 1 and 2 periods for Supplier 2. Only 30\% of variations on flexible orders are allowed.

Case 3: Suppliers 1 and 2 require a frozen horizon of respectively 3 and 2 periods.

Table 5 presents the performance of the different cases. As one might expect, the overall cost of plans decreases as the level of purchasing flexibility increases. We can therefore conclude that as the length of suppliers' frozen horizon decreases, the total cost of the supply chain decreases. The service rate is improved by increasing the flexibility of the suppliers. Case 3 gives the best operational and financial results. Indeed, Case 3 has a financial result that is very close to the ideal plan result.

To emphasize on the impact of flexibility, we present the results in the form of graphs. Fig.4, 5 and 6 present the production plans respectively from cases 1, 2 and 3. In the first case, the level of internal production exceeds by several times the standard capacity set at 65 units of products. Case 1 used extrahours to cope with the fluctuating demand. Compared to Case 1, Fig.5 shows less use of extra-hours in Case 2 because internal production peaks are lower. This is consistent with the increased use of subcontracting in this case. The use of a flexible horizon that is related to suppliers has allowed for more flexibility in production, and therefore the possibility of subcontracting part of the orders allocated to overtime production. In our example, this corresponds to the use of a less expensive solution. Fig. 6 shows that the use of subcontracting in Case 3 has further increased compared to Case 2. Case 3 confirms that the increase in reactivity improves production conditions by allowing for making less expensive decisions.

Table 5

Performance of the different cases

\begin{tabular}{llll}
\hline & Case 1 & Case 2 & Case 3 \\
\hline Service rate $(T S)$ & 97.17 & 98.11 & 98.76 \\
Index of depth of shortage $\left(I_{p r}\right)$ & 3 & 3 & 1 \\
Index of width of shortage $\left(I_{a m}\right)$ & 2 & 2 & 1 \\
Cost of adaptation $(C a)$ & 18406 & 14110 & 9724 \\
Total cost $\left(C_{t}\right)$ & 65622.72 & 61933.97 & 58548.25 \\
Occurrence of a cash deficit $\left(D_{t}\right)$ & 3 & 2 & 1 \\
$\Delta C F$ & 98173 & 102360 & 105750 \\
$\Delta G N W C$ & 126331.86 & 130176.396 & 133765.572 \\
\hline
\end{tabular}

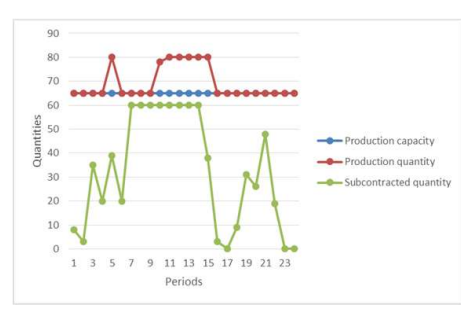

Fig. 4. Production in Case 1

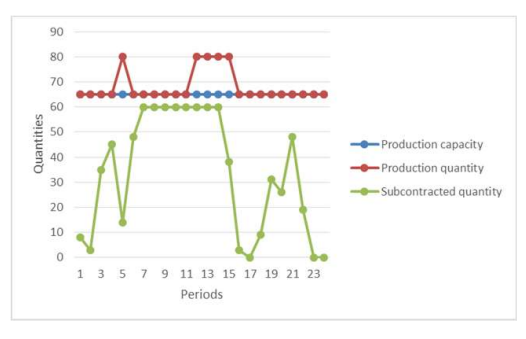

Fig. 5. Production in Case 2



Fig. 6. Production in Case 3 
According to Fig.7, the strategy adopted to absorb the variations in demand is the upstream smoothing of production. This is clear by the peaks of stocks shown in the figure. The short anticipation delay of production and outsourcing allowed for anticipated production, in order to create finished product inventories. However, the three cases do not have the same ability to anticipate. Indeed, the anticipation of production is not only related to the production system but also to the availability of components. However, the availability of components is closely linked to the reactivity of suppliers. This explains the increase in stock values with the increase in the reactivity of suppliers. In the same context, the stocks of finished products give a complementary idea on the quality of service of the different approaches.

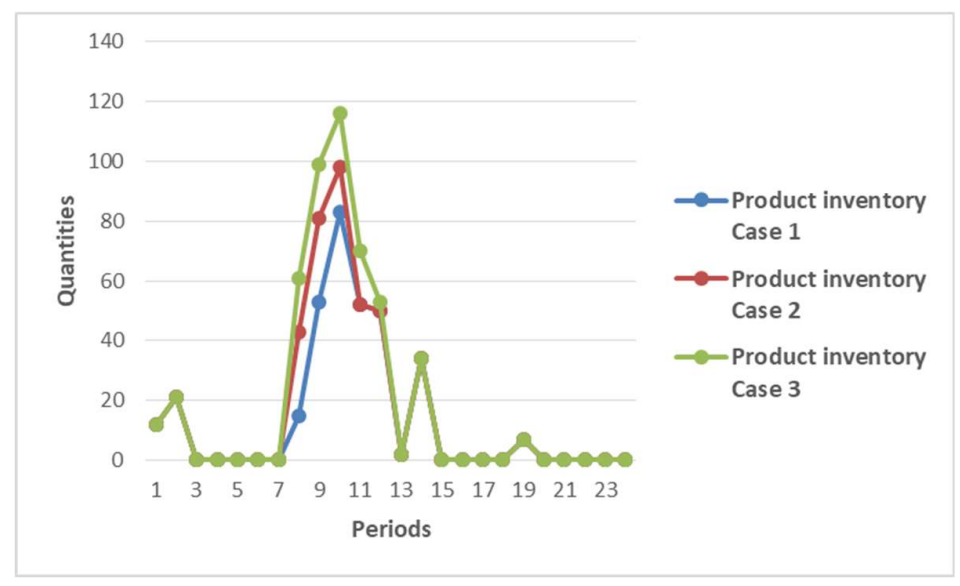

Fig.7. Product stock for the three cases

The operational costs are detailed in Table 6. They offer, in addition to the preceding graphs, a finer observation of the production process. We note the increase in logistics costs with the decrease in supplier's reactivity. This cost coexists with the use of more expensive solutions to overcome the lack of reactivity (overtime, purchases from the most expensive source).

\section{Table 6}

Operational costs for the three case studies

\begin{tabular}{llll}
\hline & Case 1 & Case 2 & Case 3 \\
\hline Total purchasing cost from Supplier 1 & 6865,47 & 7207.72 & 7221.8 \\
Total purchasing cost from Supplier 2 & 745 & 174 & 150 \\
Total supply cost & 7610,47 & 7381.72 & 7371.8 \\
Total cost of overtime & 11330 & 8250 & 4620 \\
Total cost of subcontracting & 23370 & 24210 & 25200 \\
Total cost of shortage & 5760 & 4260 & 3180 \\
\hline
\end{tabular}

Case 2 differs from Case 1 in that the second half of the frozen horizon is replaced with a flexible horizon. The addition of the flexible horizon in Case 2 allows for production smoothing and therefore less use of overtime. The increase in supplier flexibility permits the anticipation of production to avoid shortage costs, which are much more important than storage costs. Case 3 gives the best costs for all logistical decisions. In fact, the compensation of the gaps between orders established based on demand forecast and those established based on the real demand can only be made after the frozen horizon of the suppliers. As a result, the corrections that are applied must compensate for the differences over as many periods as in the frozen horizon of the supplier. In addition, the reactivity of the first supplier being insufficient, it is necessary to purchase from Supplier 2. This is a shortfall for Supplier 1 and can be highlighted in the negotiation process. 
In our example, Case 2 is a good compromise between Case 1 and Case 3 . The results show an increase of about $5 \%$ of the first supplier turnover, a decrease of approximately $5.6 \%$ of procurement costs and a decrease of about $23 \%$ of the costs of adaptation.

To enhance its reactivity, it can be important for a company to negotiate for a shorter anticipation delay against the assurance of a more important turnover to its supplier. However, it is not always easy to reduce the anticipation delay of the supplier since it is imposed by the constraints related to its production system. Hence, the need for the company to negotiate with its supplier a possible flexibility in quantities.

\subsection{Impact of supplier flexibility on a cash-distressed company}

In consistence with industrial practices, the demand horizon related to each plan is composed of a frozen zone and a free zone. The frozen or firm zone consists of the orders confirmed by the customer at the beginning of the current planning horizon. The demands of the rest of the horizon are based on forecast information following the latest demand information. This part aims to highlight the benefit of supplier flexibility when demand is overestimated.

\subsubsection{Modelling of uncertain demand}

In each iteration of the simulation procedure, the planner has at his disposal frozen and flexible orders. Several strategies are tested in the work of Gallasso et al. (2009). A myopic strategy is to conduct planning on the basis of frozen orders, without integration of flexible orders. An optimistic strategy makes it possible to integrate frozen demands and the maximum value of flexible demands. A pessimistic strategy takes into account the minimum value of flexible orders. An intermediate strategy is to consider the average of the flexible order values.

We were inspired by those strategies to test the behaviour of the chain in the different cases presented earlier. In this study, the evaluation is carried out in the worst case from the point of view of working capital requirements. This is the optimistic strategy and the firm demands correspond to the minimum values of the flexible interval.

\subsubsection{Results interpretation}

The results obtained for the three cases are summarized in Table 7. It should be noted that the change in $G N W C$ has been improved by the increase in the reactivity of the suppliers. The working capital requirement decreased considerably from Case 1 to Case 2. Fig. 8 and 9 show how the increased flexibility of suppliers leads to a less need of external financing sources, thus preventing companies from bank loans and factoring (which represents a high financial cost to the company).

In different cases, the model shows that the company could choose not to pay the amount of its invoices at the due date if its current level of net working capital is low. Indeed, the penalty for payment default is less expensive than the use of bank financing. This explains why the model choses, in some periods, the supplier with the highest purchase cost but with the possibility to pay after the due date. Indeed, our approach considers the supplier as an adjustment variable to make the most of contractual terms. Unlike the traditional approach of supply chain optimization, the model chooses the purchasing source according to the purchase cost and the available cash, as well.

Table 7

Overall Results

\begin{tabular}{lllc}
\hline & Case 1 & Case 2 & Case 3 \\
\hline$\Delta W C R$ & 11734 & 8592 & 6960 \\
$\Delta C F$ & 11738 & 17730 & 20291 \\
$\Delta G N W C$ & 23472 & 26322 & 27251 \\
\hline
\end{tabular}

In a non-integrated approach, the goal is usually to decide which of the pending invoices have to be paid on a given day (Gupta, 2011). In our approach, we choose the supplier depending on the date where the company will be able to pay a given order. The first supplier is chosen in case the invoice is paid in four 
weeks. The second supplier is chosen in two cases: the invoice will be paid in the first week to benefit from the discount or if it will be paid after the deadline to avoid more expensive sources of financing. Table 8 shows that financing costs have decreased with the use of the Supplier 2.

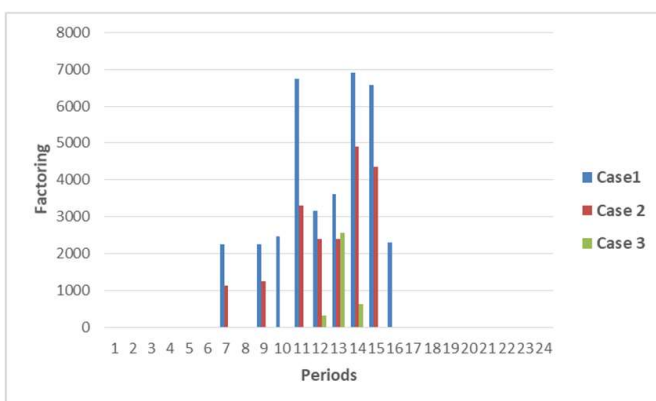

Fig. 8. Factoring per period

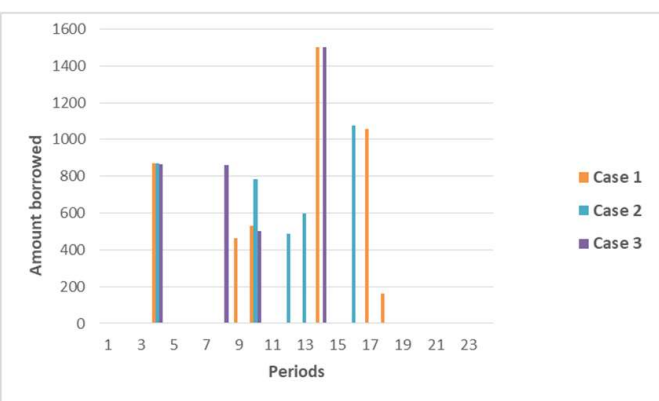

Fig. 9. Credit per period

In the example studied herein, the demands forecasts are overvalued. Therefore, a commitment to accept supplier deliveries generates a surplus stock of components and therefore increases the timing between disbursements and receipts. This temporal gap explains the increase in inventories with the decrease in supplier flexibilities, as shown on Fig.10. The longer this stock is held, the longer cash is tied up in the operational cycle. The permitted flexibility in orders' quantities gives the possibility to adjust the orders when the customer demand is frozen. Portions of the cancelled orders are replaced with orders from Supplier 2 to ovoid the liquidity shortage caused by cash offsets. These insights can explain why Case 3 uses more frequently the second purchasing source. Fig.11 and Fig.12 show the quantity purchased from Spplier 1 and from Supplier 2 for the different cases.

\section{Table 8}

Summary of results

\begin{tabular}{llll}
\hline & Case 1 & Case 2 & Case 3 \\
\hline Total purchasing cost from Supplier 1 & 2220 & 1968 & 834 \\
Total purchasing cost from Supplier 2 & 158 & 374 & 1384 \\
Total cost of supply & 40963.2 & 41085.6 & 42411.6 \\
Total financing cost & 7251,46 & 3956.402 & 697.89 \\
\hline
\end{tabular}

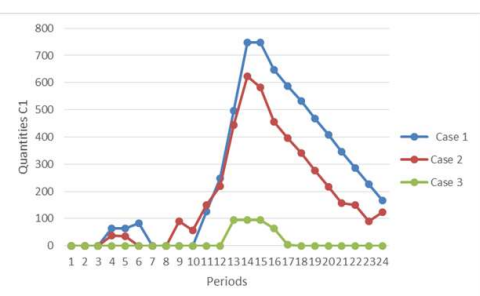

Fig. 10. Stock of components for the three cases

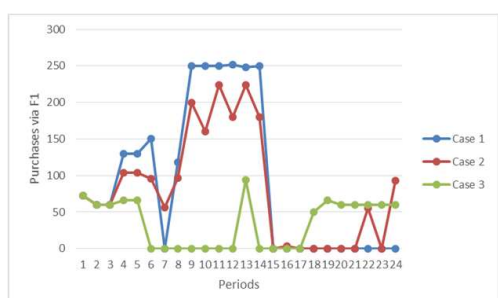

Fig. 11. Supplies made with the supplier 1

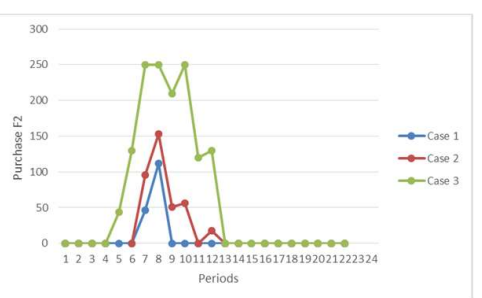

Fig. 12. Supply made with the supplier 2

It is pointed out that the reactivity and flexibility of suppliers improve the financial situation and decreases the financing needs. In fact, the increased reactivity of the supply chain reduces the operating cycle and time lag between disbursements and receipts of money. These decisions help to improve cash flow and the $G N W C$.

\section{Conclusions and perspectives}

We have developed a mixed integer-programming model to coordinate operations and financial planning at the tactical level under demand uncertainty. The ultimate objective is to find a way in which small and medium companies can improve their working capital management. The net global working capital, which is related to short-term financial decisions, has been chosen as the objective function to be maximized. Furthermore, this study addresses the question of how Quantity Flexibility (QF) Contracts can contribute to decrease financial and operational costs. In order to guaranty the applicability of 
contractual clauses, the planning model is implemented on a rolling horizon basis. This research work analyses the role of supplier's flexibility, in terms of payment and order, in decreasing tied-up working capital, which nowadays seems to be a priority. The results obtained by the proposed approach indicate that supplier's flexibility improves service level, reduces operational and financial cost and minimizes the need to finance working capital requirement. Supplier's flexibility is introduced through an increased flexibility in the timing of payment and Quantity Flexibility (QF) Contracts. Our tests have demonstrated the potential gains from business cooperation on logistical and financial results.

An interesting perspective of this work would be to consider currency fluctuation uncertainty and operational and financial hedging strategies.

\section{Acknowledgements}

This research has been conducted within a MOBIDOC thesis framework of PASRI program that is supported by the European Union.

\section{References}

Amrani, A., Deschamps, J.C., \& Bourrières, J.P. (2012). The impact of supply contracts on supply chain product-flow management. Journal of Manufacturing Systems, 31(2), 253-266.

Badell, M., Romero, J., Huertas, R., \& Puigjaner, L. (2004). Planning, scheduling and budgeting valueadded chains. Computers and Chemical Engineering, 28(1-2), 45-61.

Bal, A. B., Elliot, V., Lindblom, T., Malmberg, L.-G., Rajput, T., \& Woxenius, J. (2018). Different Perspectives on Supply Chain Finance-In Search of a Holistic Approach. Finance and Risk Management for International Logistics and the Supply Chain, 35-54.

Bassok, Y. \& Anupindi R. (2008). Analysis of supply contracts with commitments and flexibility. Naval Research Logistics, 55(5), 459-77.

Shen, B., Choi, T.M., \& Minner, S. (2018). A review on supply chain contracting with information considerations: information updating and information asymmetry. International Journal of Production Research, 1-39. https://doi.org/10.1080/00207543.2018.1467062

Brealey, R., Myers, S.C., \& Allen, F. (2011). Principles of Corporate Finance. Tata McGraw-Hill Education.

Cao, M. \& Zhang, Q. (2010). Supply chain collaborative advantage: A firm's perspective. International Journal of Production Economics, 128 (1), 358-367.

Chen, X.F., \& Hu, C.X. (2011). The value of supply chain finance. Supply Chain ManagementApplications and Simulations, 111-132.

Comelli, M., Féniès, P., \& Tchernev, N. (2008). A combined financial and physical flows evaluation for logistic process and tactical production planning: Application in a company supply chain. International Journal of Production Economics, 112(1), 77-95.

Dada, M., \& Hu, Q. J. (2008). Financing newsvendor inventory. Operations Research Letters, 36(5), 569-573.

Demirguc-Kunt, A., \& Vojislav, M. (2002). Firms as Financial Intermediaries: Evidence from Trade Credit Data. World Bank Working Paper.

Deloof, M. (2003). Does working capital management affect profitability of Belgian firms? Journal of Business Finance and Accounting, 30, 573-587.

Fabbri, D., \& Klapper, L. (2009). Trade credit and the supply chain. Working paper. University of Amsterdam, Netherlands.

Galasso, F., Mercé, C., \& Grabot, B. (2009). Decision support framework for supply chain planning with flexible demand. International Journal of Production Research, 47(2), 455-478.

Grossman, S., \& Hart, O. (1986). The costs and benefits of ownership: a theory of vertical and lateral integration. Journal of Political Economy, 94(4), 691-719.

Guillén-Gosálbez, G., Badell, M., Espuña, A., \& Puigjaner, L. (2006). Simultaneous optimization of process operations and financial decisions to enhance the integrated planning/scheduling of chemical supply chains. Computers and Chemical Engineering, 30, 421-436. 
Gupta, S., \& Dutta, K. (2011). Modeling of financial supply chain. European Journal of Operational Research, 211(1), 47-56.

Hahn, G. J., \& Kuhn, H. (2012) Simultaneous investment, operations, and financial planning in supply chains: A value-based optimization approach. International Journal of Production Economics, 140, 559-569.

Heydari, J., Rastegar, M., \& Glock, C. H. (2017). A two-level delay in payments contract for supply chain coordination: The case of credit-dependent demand. International Journal of Production Economics, 191, 26-36.

Hofmann, E. (2005). Supply Chain Finance: some conceptual insights. Beiträge Zu Beschaffung Und Logistik, 203-214.

Lainez, J. M., Guillén-Gosálbez, G., Badell, M., Espuna, A., \& Puigjaner, L.(2007). Enhancing corporate value in the optimal design of chemical supply chains. Industrial and Engineering Chemistry Research, 46, 7739-7757.

Laínez, J. M., Puigjaner, L., \& Reklaitis, G. V. (2009). Financial and financial engineering considerations in supply chain and product development pipeline management. Computers and Chemical Engineering, 33, 1999-2011.

Lalami, I., Frein, Y., \& Gayon, J. P. (2017). Production planning in automotive powertrain plants: a case study. International Journal of Production Research, 55(18), 5378-5393.

Longinidis, P., \& Georgiadis, M.C. (2011). Integration of financial statement analysis in the optimal design of supply chain networks under demand uncertainty, International Journal of Production Economics, 129, 262-276.

Longinidis, P., \& Georgiadis, M.C. (2013). Managing the trade-offs between financial performance and credit solvency in the optimal design of supply chain networks under economic uncertainty. Computers and Chemical Engineering, 48, 264-279.

Longinidis, P., Georgiadis, M. C., \& Kozanidis, G. (2015). Integrating operational hedging of exchange rate risk in the optimal design of global supply chain networks. Industrial \& Engineering Chemistry Research, 54(24), 6311-6325.

Lian, Z., \& Deshmukh, A. (2009). Analysis of supply contracts with quantity flexibility. European Journal of Operational Research, 196(2), 526-533.

Lin, P.C., \& Uzsoy, R. (2016). Chance-constrained formulations in rolling horizon production planning: an experimental study. International Journal of Production Research, 54(13), 3927-3942.

Lin, Q., Su, X., \& Peng, Y. (2018). Supply chain coordination in confirming warehouse financing. Computers \& Industrial Engineering, 118, 104-111.

Luo, W. \& Shang, K. (2013). Managing inventory for entrepreneurial firms with trade credit and payment defaults. Available at SSRN, 2013.

Klapper, L. (2006). The role of factoring for financing small and medium enterprises. Journal of Banking and Finance, 30(11), 3111-3130.

Klapper, L., Laeven, L., \& Rajan, R. (2011). Trade credit contracts. The Review of Financial Studies, 25(3), 838-867.

Kim, J. S., Park, S. I., \& Shin, K. Y. (2014). A quantity flexibility contract model for a system with heterogeneous suppliers. Computers and Operations Research, 41, 98-108.

Meltzer, A. (1960). Mercantile credit, monetary policy and the size of firms. Review of Economics and Statistics, 42(4), 429-437.

Mian, S.L., \& Smith, C.W. (1992). Accounts receivable management policy: Theory and evidence. The Journal of Finance, 47(1), 169-200.

Nickel, S., Saldanha-da-Gama, F., \& Ziegler, H. P. (2012). A multi-stage stochastic supply network design problem with financial decisions and risk management. Omega, 40(5), 511-524.

Petersen, M. A., \& Rajan, R. G. (1997). Trade credit: theories and evidence. The Review of Financial Studies, 10(3), 661-691.

Pfohl, H.C., \& Gomm, M. (2009). Supply chain finance: Optimizing financial flows in supply chains. Logistics Research, 1(3), 149-161. 
Protopappa-Sieke, M., \& Seifert, R. W. (2010). Interrelating operational and financial performance measurements in inventory control. European Journal of Operational Research, 204(3), 439-448.

Protopappa-Sieke, M. \& Seifert, R.W. (2017). Benefits of working capital sharing in supply chains. Journal of the Operational Research Society, 68 (5), 521-532.

Puigjaner, L., \& Guillén-Gosálbez, G. (2008). Towards an integrated framework for supply chain management in the batch chemical process industry. Computers \& Chemical Engineering, 32(4-5), 650-670.

Puigjaner, L., \& Laínez, J. M. (2008). Capturing dynamics in integrated supply chain management. Computers and Chemical Engineering, 32(11), 2582-2605.

Romero, J., Badell, M., Bagajewicz, M. J., \& Puigjaner, L. (2003). Integrating budgeting models into scheduling and planning models for the chemical batch industry. Industrial and Engineering Chemistry Research, 42(24), 6125-6134.

Sethi, S. P., Yan, H., \& Zhang, H. (2004). Quantity flexibility contracts: optimal decisions with information updates. Decision Sciences, 35(4), 691-712.

Sharma, P., Sarker, B.R., \& Romagnoli, J.A. (2011). A decision support tool for strategic planning of sustainable biorefineries. Computers and Chemical Engineering, 35(9), 1767- 1781.

Shen, B., Choi, T.M., \& Minner, S. (2018). A review on supply chain contracting with information considerations: information updating and information asymmetry. International Journal of Production Research, 1-39. https://doi.org/10.1080/00207543.2018.1467062

Sodhi, M.S., \& Tang, C.S. (2009). Modeling supply-chain planning under demand uncertainty using stochastic programming: a survey motivated by asset-liability management. Productions Economics, $121,728-738$.

Sodhi, M. S., \& Tang, C. S. (2012). Tactical approaches for mitigating supply chain risks: Financial and operational hedging, in: Managing supply chain risk (pp. 109-133). Springer, Boston, MA.

Sopranzetti, B. J. (1998). The economics of factoring accounts receivable. Journal of Economics and Business, 50(4), 339-359.

Soufani, K. (2002). On the determinants of factoring as a financing choice: evidence from the UK. Journal of Economics and Business, 54(2), 239-252.

Steinrücke, M., \& Albrecht, W. (2016). A flow-to-equity approach to coordinate supply chain network planning and financial planning with annual cash outflows to an institutional investor. Business Research, 9(2), 297-333.

Tsay, A. A. (1999). The Quantity Flexibility Contract and Supplier-Customer Incentives. Management Science, 45(10), 1339-1358.

Tsay, A. A., \& Lovejoy, W. S. (1999). Quantity flexibility contracts and supply chain performance. Manufacturing \& Service Operations Management, 1(2), 89-111.

Yang, S. A., \& Birge, J. R. (2013). How inventory is (should be) financed: Trade credit in supply chains with demand uncertainty and costs of financial distress. Available at SSRN 1734682.

Yi, G., \& Reklaitis, G.V. (2004).Optimal design of batch-storage network with financial transactions and cash flows. AIChE Journal, 50(11), 2849-2865.

Walsh, P.M., Williams P.A., \& Heavey, C. (2008) Investigation of rolling horizon flexibility contracts in a supply chain under highly variable stochastic demand. IMA Journal of Management Mathematics, 19(2), 117-35.

Zeballos, A.C, Seifert, RW., \& Protopappa-Sieke, M. (2013). Single product, finite horizon, periodic review inventory model with working capital requirements and short-term debt. Computers and Operations Research, 40(12), 2940-2949.

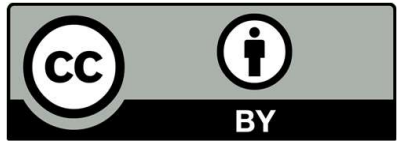

(C) 2019 by the authors; licensee Growing Science, Canada. This is an open access article distributed under the terms and conditions of the Creative Commons Attribution (CCBY) license (http://creativecommons.org/licenses/by/4.0/). 